\title{
Remediation of Monoethanolamine after Exposure to Brown Coal Flue Gases
}

\author{
By

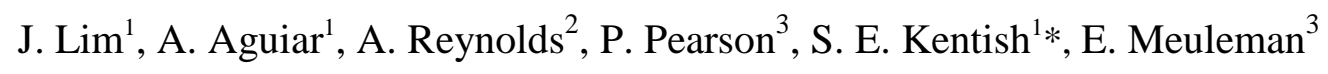 \\ ${ }^{1}$ CRC for Greenhouse Gas Technologies (CO2CRC), Department of Chemical and \\ Biomolecular Engineering, The University of Melbourne, Parkville, Vic. 3010 Australia. \\ ${ }^{2}$ School of Applied Sciences and Engineering, Faculty of Science, Monash University, Vic. \\ 3800 Australia
}

${ }^{3}$ CSIRO Energy Flagship, Bayview Ave, Clayton, Vic., Australia.

\begin{abstract}
Monoethanolamine (MEA) is the solvent most commonly considered for post-combustion capture. However, the solvent will accumulate a range of contaminants during use, notably heat stable salts, that reduce its performance. This work considers the removal of these contaminants from MEA solutions that had been exposed to over 50 and 1800 hours of post combustion capture of flue gases from a brown coal-fired power station. Analysis indicated that these MEA solutions contained significant quantities of heat stable salts including iron, potassium, sulphate, nitrate and organic anions, particularly in the older sample. Both solutions were initially neutralised to free the protonated amine, which led to precipitation of some impurities within the older solvent. Nanofiltration was considered as an approach to further concentrate impurities, but was ineffective due to low permeation rates and low rejection of monovalent salts, at less than $20 \%$. It was effective in concentrating metal contaminants and may be useful into the future for this reason. Conversely, electrodialysis was effective in removing up to $91 \%$ of the ionic content of the solutions, although the current efficiency fell at low feed conductivities. Monovalent salts such as sodium, potassium and nitrate were removed more readily than multivalent salts such as iron and sulphate. MEA loss was consistent with our prior work at around $0.15 \mathrm{~g} / \mathrm{m}^{2} . \mathrm{s}$ and was predominantly as the free amine rather than the carbamate salt.
\end{abstract}

\section{*Corresponding Author}

sandraek@unimelb.edu.au

Keywords: nanofiltration; electrodialysis; sulfate; nitrate 


\section{INTRODUCTION}

The use of monoethanolamine (MEA) to capture carbon dioxide is a common operation in natural gas sweetening and is considered as the baseline solvent for the large scale capture of this greenhouse gas from post combustion flue gas streams[1]. However, over time, the MEA accumulates impurities [2, 3]. Anionic impurities include heat stable salts such as formate, oxalate and acetate from reactions with residual oxygen[4], sulphites, sulfates from reaction with SOx and nitrates and nitrites from reaction with NOx[5]. Chlorides can also accumulate from residual $\mathrm{HCl}$ in the flue gas stream[6]. These anions are generally associated with protonated amines $\left(\mathrm{MEAH}^{+}\right)$, but ammonium cations may also form and metal cations such as $\mathrm{Fe}, \mathrm{Cu}$ and $\mathrm{Ni}$ can also accumulate through corrosion[7]. Oligomers and polymers can also form through thermal degradation[6]. These impurities impair operation by reducing the total MEA strength and also by increasing the solvent viscosity. Further, they lead to increased rates of equipment corrosion, which ultimately results in necessary replacement.

In natural gas sweetening operations, these impurities are often removed simply by routine solvent replacement. However, this approach is unlikely to be economic for large scale carbon capture. The addition of $\mathrm{NaOH}$ or a similar alkali can be used to release the protonated amine and recover this solvent component. This process is referred to as neutralisation, although the $\mathrm{pH}$ of the total solution actually deviates further from neutrality during this step (Equation 1):

$$
\mathrm{MEAH} \mathrm{H}^{+}+\mathrm{OH}^{-} \rightarrow \mathrm{MEA}+\mathrm{H}_{2} \mathrm{O}
$$

Neutralisation may also result in some conversion of the carbamate anions to bicarbonate and carbonate species, as these are more stable at the elevated $\mathrm{pH}[8]$. In turn, this may lead to precipitation of some salts [9]. The salts precipitated during neutralisation and other solid impurities can be removed by filtration. However, even with such neutralisation and filtration, the solvent inevitably builds in concentration of heat stable anions and undesirable metal cations, which can lead to increased corrosion rates. Further purification is required to remove these ionic impurities. Thermal reclamation is the most well known approach for solvent purification and involves evaporation of the amine solution, leaving behind a sludge containing the contaminants for disposal[10]. Alternatively, in ion exchange, the contaminated solvent is passed through a sequence of beds packed with ion exchange resin. The charged impurities are adsorbed onto the resin material, releasing either $\mathrm{H}^{+}$or $\mathrm{OH}^{-}$ions in exchange. The bed is later regenerated through the passage of an acid or base, which 
releases the impurities into a wastewater stream and replaces the $\mathrm{H}^{+}$and $\mathrm{OH}^{-}$ions on the resins. A third option is electrodialysis(ED), which operates by passing an electrical current across a stack of alternating cation selective and anion selective membranes[11, 12] (Figure 1). Charged impurities pass across the membranes in response to the electrical field, but their movement is restricted when they encounter a membrane of opposing selectivity. This causes these impurities to accumulate in every second channel, forming what is known as the concentrate stream. Conversely, charged impurities are depleted from the alternate channels, forming the diluate stream, which in the present case is purified MEA.

In our prior work, we have also considered nanofiltration (NF) to concentrate the salts within a contaminated solvent and thus reduce the scale and increase the efficiency of downstream electrodialysis. Nanofiltration is a pressure driven membrane process but one that also uses a charged membrane. In this case, the salts are concentrated in the retentate stream, as they are rejected from the membrane due to their charge. Clean neutral MEA permeates the membrane and can be returned to the main solvent process.

While the clean-up of these impurities will be an important component of any postcombustion capture process, there is little information on the efficacy of various approaches in practice. Sexton et al.[13] provide a comparison based on desktop simulation, but do not provide any experimental data on these operations. Both Volkov et al. [14] and our own prior work[15, 16] presents results based on synthetic solutions prepared in the laboratory. However, data from experiments with amine solutions after exposure to real flue gases is very limited. Vitse et al. [17] show that electrodialysis combined with mechanical filtration can be effective in maintaining the concentration of heat stable salts below $0.5 \mathrm{wt} \%$ in a proprietary advanced amine solvent (Dow UCARSOL ${ }^{\mathrm{TM}}$ FGC 3000), but provide no process information on the operation of the ED unit. Bazehnov et al. [18] describe a two stage ED operation tested on an MEA solution that was capturing carbon dioxide from a bituminouscoal fired power station for up to 1000 hours of operation. In single stage operation, the total anion concentration was reduced from $2.3 \mathrm{~g} / \mathrm{L}$ to $0.9 \mathrm{~g} / \mathrm{L}$ within an hour, with all anions including nitrate, sulfate, formate, acetate and oxalate reducing substantially in concentration. However, the concentration of heavy metal cations was not reduced.

In the present work, we test the viability of both nanofiltration and electrodialysis to clean up MEA solutions of around $25 \mathrm{wt} \%$ amine, that have been used for $50+$ and $1800+$ hours respectively in flue gas capture. The solutions were generated from the capture of carbon 
dioxide from the flue gases of the AGL Loy Yang coal-fired power station in the Latrobe Valley, Victoria by CSIRO Australia. The aim of the work is to validate whether these processes can be effective when applied to amine solutions that have been exposed to post combustion flue gases and to provide data for future workers on the process parameters that provide optimum performance.

\section{EXPERIMENTAL}

\subsection{Materials}

Aged MEA (MEA1800+[19] and MEA50+) was sourced from the Post-combustion Carbon Capture pilot plant owned and operated by the CSIRO at AGL Loy-Yang power station and described in detail by Artanto et al.[20, 21]. This power station uses Victorian brown coal and the concentrations of NOx and SOx in the flue gas are substantial (150 - 250 ppm NOx (of which $>98.5 \%$ is NO) and $120-200$ ppm SOx) [21]. However, $\mathrm{SO}_{2}$ and some NOx (the part that is not NO) is washed off in a pre-treatment column fed with $32 \mathrm{wt}$.\% $\mathrm{NaOH}$ to keep the $\mathrm{pH}$ between 8.5 and 9.2, so that the concentrations that reach the MEA absorber are 120245pm NO and $<10 \mathrm{ppm} \mathrm{SO}_{2}$.

The MEA had been stored for some months prior to delivery and hence it is possible that some carbamate anions had been converted to bicarbonate species. It is well known that carbamates will undergo such a reaction, but it is usually too slow to be relevant in active post-combustion capture operations[22].

\subsection{Solution Pretreatment}

Both NF and ED processes operate best at low $\mathrm{CO}_{2}$ loadings [9], where the carbamate concentrations are minimized. While the $\mathrm{CO}_{2}$ loading of the MEA $1800+$ was reasonably low as received (0.12, see Table 1 ), the $\mathrm{CO}_{2}$ loading of the MEA $50+$ was 0.31 , too high for effective ED or NF. Hence, this loading was reduced by simple boiling of the solution prior to use. In industrial practice, the solution for reclamation would be taken from the cool, lean solvent circuit, where the $\mathrm{CO}_{2}$ loading should be less than 0.15 . 
Table 1 - The physical and chemical properties of aged MEA solvents before and after the pre-treatment steps

\begin{tabular}{|l|c|c|c|c|c|}
\hline & \multicolumn{3}{|c|}{ MEA 50+ } & \multicolumn{2}{c|}{ MEA 1800+ } \\
\hline & As received & $\begin{array}{c}\text { After } \\
\text { boiling }\end{array}$ & $\begin{array}{c}\text { After boiling, } \\
\text { neutralisation }\end{array}$ & $\begin{array}{c}\text { As } \\
\text { received }\end{array}$ & $\begin{array}{c}\text { After } \\
\text { neutralisation }\end{array}$ \\
\hline $\begin{array}{l}\text { Conductivity } \\
(\mathrm{mS} / \mathrm{cm})\end{array}$ & 12.7 & & 14.5 & 13.5 & 15.3 \\
\hline Density (kg/m $\left.{ }^{3}\right)$ & 1029 & & - & 1076 & - \\
\hline Viscosity (mPa.s) & 2.4 & & 2.4 & 4.3 & 4.3 \\
\hline pH & 10.3 & & 12.45 & 10.64 & 12.3 \\
\hline $\begin{array}{l}\text { MEA concentration } \\
(\text { wt\%) }\end{array}$ & $22.3 \pm 0.4$ & 23.5 & 19.1 & $27.0 \pm 0.7$ & 24.0 \\
\hline $\begin{array}{l}\mathrm{CO} \text { loading } \\
\left(\mathrm{mol} \quad \mathrm{CO}_{2} / \mathrm{mol}\right.\end{array}$ & 0.31 & & 0.13 & 0.12 & 0.14 \\
\hline \begin{tabular}{l} 
MEA) \\
\hline
\end{tabular}
\end{tabular}

(Measurements were conducted at approximately $23^{\circ} \mathrm{C}$ )

Thermal boiling of MEA50+ solvent was carried out in batches using a 2 L round bottom flask with a condenser. The flask was filled with $1.5 \mathrm{~L}$ solvent and heated to a temperature of $110-120^{\circ} \mathrm{C}$ at atmospheric pressure. Cold water (single pass) was used in the condenser to reduce the loss of MEA through evaporation. Small samples (approx. $5 \mathrm{~mL}$ ) were taken periodically to monitor the loss of MEA and $\mathrm{CO}_{2}$ from the solution. The boiling was continued until the measured $\mathrm{CO}_{2}$ loading was less than $0.15 \mathrm{~mol} \mathrm{CO}_{2} / \mathrm{mol}$ MEA (Table 1). The boiled solution was then cooled to room temperature and combined with other batches prior to use.

Both MEA50+ and MEA1800+ were neutralised prior to use by adding $10 \mathrm{M} \mathrm{NaOH}$ until the $\mathrm{pH}$ was approximately 12.4. The amount of $\mathrm{NaOH}$ added was approximately $300 \mathrm{~mL}$ for $3 \mathrm{~L}$ MEA50+ solution $(0.9 \pm 0.4 \mathrm{~mol} \mathrm{NaOH}$ per $\mathrm{L}$ of feed solution) and $400 \mathrm{~mL}$ for $3 \mathrm{~L}$ MEA1800+ solution (1.4 $\pm 0.2 \mathrm{~mol} \mathrm{NaOH}$ per L of feed solution). Neutralisation reduced the MEA concentration in both samples by approximately $10 \%$, due to the additional volume of $\mathrm{NaOH}$ solution added. The addition of $\mathrm{NaOH}$ also increased the solution conductivity by approximately $2 \mathrm{mS} / \mathrm{cm}$ due to the presence of more ionic species in the sample (Table 1). 


\subsection{Microfiltration and Nanofiltration}

All microfiltration (MF) and nanofiltration (NF) tests were conducted using a Sepa CF crossflow filtration unit (Sterlitech Corporation, USA) with a membrane active surface area of 140 $\mathrm{cm}^{2}$ as previously reported [16]. The thickness of the feed and permeate spacers used was 1.2 and $0.35 \mathrm{~mm}$ respectively. The feed solution was re-circulated through the cell at a flow rate of $1.5 \mathrm{~L} / \mathrm{min}$ using a centrifugal pump. The transmembrane pressure was maintained with a back pressure controller located at the concentrate outlet. The permeate flowrate was continuously recorded by a mass balance (A\&D Weighing, GF-400 series). The rejection (R) of charged salts was calculated by Equation 2 .

$R=1-\frac{c_{p}}{c_{F}}$

Where $c_{p}$ is the permeate concentration and $c_{F}$ is the feed concentration. In this case, the permeate is the purified MEA.

A flat sheet $0.2 \mu \mathrm{m}$ PTFE membrane with polypropylene non-woven support layer (Sterlitech Corporation, USA) was used for MF at a transmembrane pressure of $300 \mathrm{kPa}$. A Koch SelroMPF-34 membrane was used in all NF experiments with the transmembrane pressure varying from 1000 to $3000 \mathrm{kPa}$ in a random order. New membranes were used in each experiment and each membrane was pre-treated by overnight soaking in purified water. The NF membranes were also compacted prior to use by 6 hours compression at $3000 \mathrm{kPa}$.

\subsection{Electrodialysis}

Electrodialysis was conducted on solutions that had been boiled, neutralised and undergone microfiltration, but not nanofiltration. This step used an FT-ED-40 module (FumaTechGmbH, Germany) with effective membrane area per cell $36 \mathrm{~cm}^{2}$ as previously reported[15]. The potential difference was generated by a DC power supply (Delta Elektronika, Netherlands, SM7020-D series) with an output voltage range of 0-70 V and output current range of 0-20 A. Neosepta (AHA, CMB) ion-exchange membranes (Astom, Japan) were selected due to the combination of membrane stability and low electrical resistance. In accordance with the manufacturer's recommendations, these membranes were soaked overnight in $2 \mathrm{~g} / \mathrm{L} \mathrm{KCl}$ prior to use. 
All ED experiments were conducted in batch mode with two cell pairs at a current of 278 $\mathrm{A} / \mathrm{m}^{2}$, using initial feed and concentrate volumes of $1.5 \mathrm{~L}$ and an electrode solution volume of 3 L. The arrangement of the stack (Figure 1) allows for some transfer of cations from the electrode to the concentrate solution and from the diluate to the electrode tank, but anions are prevented from moving to or from the electrode tank. Such movement of cations into and from the electrode tank is necessary to allow the electrical current to be carried. The movement becomes irrelevant in a full scale module, where there are hundreds of unit cells. However, in this lab scale apparatus, these flows must be included in mass balance calculations if they are to be solved correctly. The initial concentrate composition was $5 \mathrm{~g} / \mathrm{L}$ $\mathrm{KCl}$, while the electrode solution was $50 \mathrm{~g} / \mathrm{L} \mathrm{K}_{2} \mathrm{SO}_{4}$. The flow rate of the electrode solution was $1700 \mathrm{~mL} / \mathrm{min}$ while the flow rate of the diluate and concentrate was kept equal and constant at $200 \mathrm{~mL} / \mathrm{min}(100 \mathrm{ml} /$ minute per cell). The solutions were circulated through the membrane cells for 20 minutes prior to the initial application of an electrical potential. Each experiment was conducted over several days of operation, with the electrical potential switched off each evening, prior to the experiment re-commencing the following morning.

\subsection{Analytical Techniques}

Solution conductivity was measured during experiments using a TPS WP-81 pH, temperature and conductivity meter (Thermo Fisher Scientific).

The concentration of MEA was determined by conductometric titration with $\mathrm{HCl}$ and then $\mathrm{NaOH}$ to quantify the amount of free and bound amine respectively [23]. The sum of free and bound amine was taken as the concentration of MEA in the solution. $\mathrm{CO}_{2}$ loading was determined by titrating the MEA solutions with $2 \mathrm{M} \mathrm{HCl}$ solution using a Chittick $\mathrm{CO}_{2}$ analyser [24].

Solution viscosity was measured using a Canon Fenske viscometer and solution density was measured using a $25 \mathrm{~mL}$ density bottle.

The solids concentration within neutralised samples was determined by filtration and drying of these solids at $110^{\circ} \mathrm{C}$ and $-20 \mathrm{kPa}$ and recording the mass. The proportion of inorganic matter was further determined by recording the mass after ashing at $600^{\circ} \mathrm{C}$.

The concentration of sulfate and nitrate within aqueous solutions was quantified using ion chromatography (IC) (Dionex ICS-1000, AS14 column) with a mixture of $2.7 \mathrm{mM}$ carbonate 
and $1 \mathrm{mM}$ bicarbonate as the eluent. IC could only be performed when the MEA concentration was low, due to the incompatibility of the analytical instruments with organic materials. A number of metal cations, as well as sulphur were quantified using Inductively Coupled Plasma - Optical Emission Spectroscopy (ICP-OES) on both aqueous and MEA containing solutions. The aqueous solutions (electrodialysis concentrate) were diluted to analytical volume with purified water and then analysed on a Varian 720 ICP-OES. The MEA containing solutions were acidified with 1:1 $\mathrm{HNO}_{3}$ : water, diluted to analytical volume with $10 \% \mathrm{HNO}_{3}$ and then analysed on a Varian Vista-Pro ICP-OES. Sc was used as internal standard in this latter case.

Changes to the membrane chemistry were evaluated by attenuated total reflection Fourier transform infrared spectroscopy (ATR-FTIR) analysis. The spectra were obtained using a PerkinElmer Frontier IR Dual-Range spectrometer equipped with a universal ATR accessory (Diamond/ZnSe crystal) and PerkinElmer Spectrum software version 10.03.08.0135. Each spectrum was collected from an average of 32 scans with the wave number ranging from 500 to $4000 \mathrm{~cm}^{-1}$ at $32 \mathrm{~cm}^{-1}$ resolution.

\section{RESULTS AND DISCUSSION}

The solvents were clear brown solutions of relatively low viscosity upon delivery (see Table 1). As a comparison, the viscosity of a pure 25 wt\% MEA solution is $2.12 \mathrm{mPa}$.s [25]. The metals of greatest significance within the solutions were calcium, iron, potassium and zinc (Figure 2).

\subsection{Neutralisation and Microfiltration}

Neutralisation resulted in the precipitation of some solid material, which could be visually observed to settle at the bottom of the sample containers. These solids were gelatinous and dark brown in color. The solid concentration was quantified as $7.1 \mathrm{~g} / \mathrm{L}$ for the MEA $1800+$ sample after neutralisation, but less than $0.2 \mathrm{~g} / \mathrm{L}$ for the MEA 50+ sample (Table 2). The solids were dried at $110^{\circ} \mathrm{C}$, ensuring the complete conversion of bicarbonate to carbonate prior to ashing at $600^{\circ} \mathrm{C}$. ICP analysis of the solid collected from the MEA1800+ showed that $40 \%$ of this dry weight was sodium cations, arising from the addition of $\mathrm{NaOH}$ as a neutralising agent. A further $31 \%$ were volatile at $600^{\circ} \mathrm{C}$. These volatile solids are likely to be 
organic acids and organic cations such as MEA [9]. The remaining 28\% solids are likely to be inorganic anions such as hydroxide and carbonate.

Table 2 - Analysis of the solid matter precipitated following neutralisation of the MEA1800+ sample

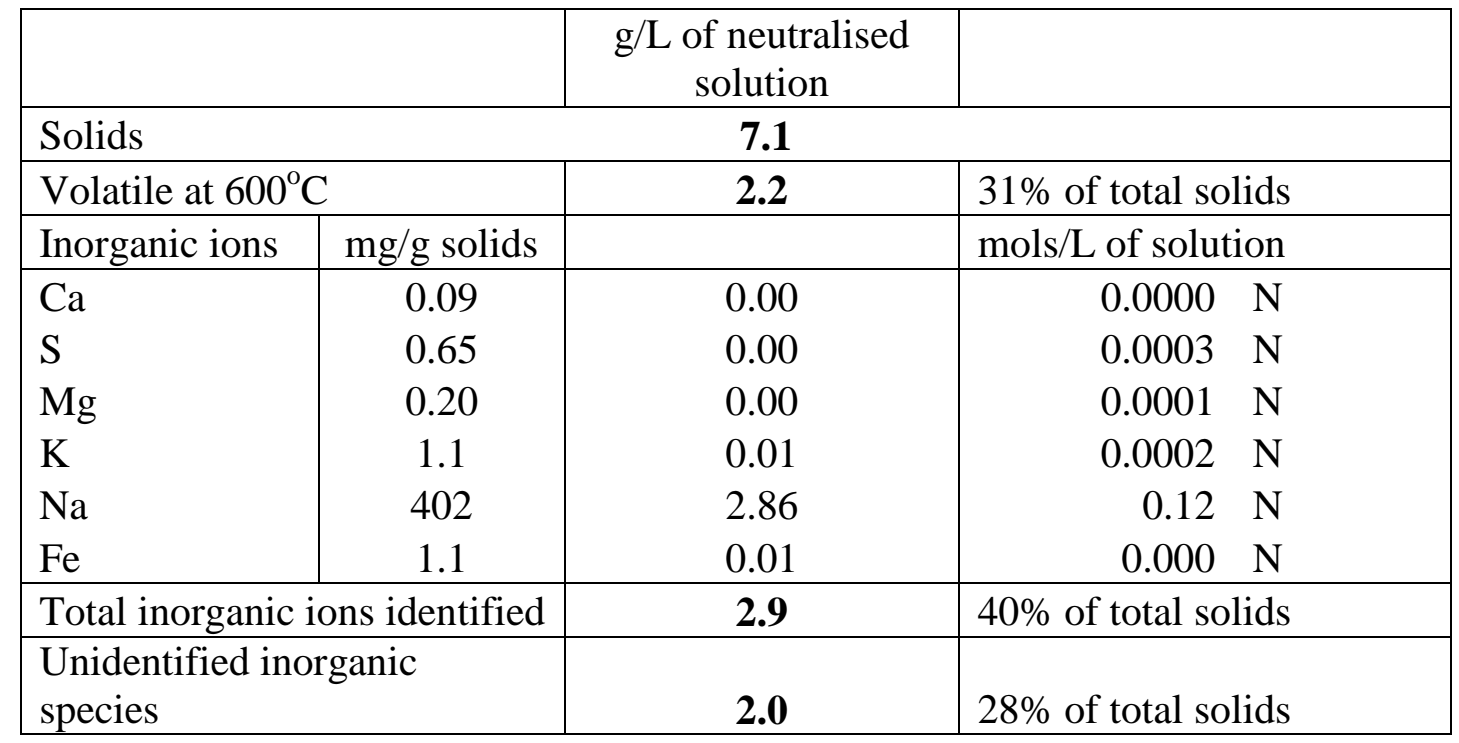

These precipitates were then removed from the solvent by microfiltration. However, it was noted that a very small quantity of solids continued to precipitate from solution for some days after the neutralisation and microfiltration procedure. This may have been due to further reaction of the solutions with atmospheric carbon dioxide.

\subsection{Nanofiltration}

In our prior work[16], with laboratory prepared solutions of $30 \mathrm{wt} \% \mathrm{MEA}$ at zero $\mathrm{CO}_{2}$ loading, we obtained a reasonable flux of purified MEA through an NF membrane, with the impurity salts retained (Figure 3). However, the permeate flux for MEA50+ fell by a factor of up to 10 relative to these results; while the permeate flux for MEA1800+ solvent reduced by a factor of 60. For example, at $3000 \mathrm{kPa}$ transmembrane pressure, the flux of a laboratory prepared solution was 19 litres $/ \mathrm{m}^{2}$.hr, while that of the MEA50+ was 5.6 litres $/ \mathrm{m}^{2} . h r$ and that of the MEA $1800+$ was 0.57 litres $/ \mathrm{m}^{2}$.hr (Figure 3).

The loss of performance partly reflects the increasing osmotic pressure imposed by the retained solution. As the $\mathrm{CO}_{2}$ loading of both solutions is around 0.13 , there is a significant concentration of carbamate and/or carbonate anions in solution in addition to the impurity salts such as formates, sulfates and nitrates. These retained species add significantly to the 
osmotic pressure difference across the membrane. The osmotic pressure is given by the $\mathrm{x}$ intercept of the flux versus pressure curve, suggesting values of $920 \mathrm{kPa}$ for the MEA50+ solution and $1450 \mathrm{kPa}$ for the MEA1800+ solution. This corresponds to a total concentration of retained charged species of around 0.37 and $0.58 \mathrm{~mol} / \mathrm{L}$, which is consistent with the concentration later recovered using electrodialysis. The use of microfiltration upstream of nanofiltration here has little effect on the final results, indicating that membrane fouling is not the cause of the loss in flux.

The gradient of the flux curve also falls. This fall in gradient can partially be explained by the increased viscosity of the solution, particularly for the MEA1800+ solution (Table 1), as it is well known that solution viscosity is directly proportional to the membrane resistance. The flux was stable as a function of time, indicating that fouling is not the cause of the reduction in flux. It is possible that this further reduction arises from concentration polarisation, but this was not explicitly investigated.

The rejection of charged salts is also reduced under these conditions (Table 3), relative to simple solutions of a single salt in pure MEA, where values of greater than $80 \%$ were recorded. This loss of performance again relates to the non-zero $\mathrm{CO}_{2}$ loading and also the significant concentrations of both sodium cations added during the neutralisation step and organic anions. The total reduction in solution conductivity is less than $20 \%$, which implies that the majority of monovalent salts, specifically sodium salts, are not strongly rejected. However, it is noteworthy that the multivalent salts, specifically the heavy metals such as Fe, are more strongly rejected.

Table 3 -The conductivity of the feed and permeate solution in the NF MEA50+ experiment and the estimated total rejection of specific charged species. The transmembrane pressure was $1000 \mathrm{kPa}$ unless otherwise stated.

\begin{tabular}{|l|c|c|c|}
\hline & Feed & Permeate & Rejection(\%) \\
\hline & & $\begin{array}{c}12.2 \\
12.4(\text { at } 2000 \mathrm{kPa})\end{array}$ & 17 \\
Conductivity (mS/cm) & 15.0 & 12.9 (at 3000 kPa) & 14 \\
\hline Metal (mg/L) & & & \\
\hline Ca & $4.8 \pm 0.6$ & 4 & 17 \\
\hline Cr & $2.3 \pm 0.1$ & 0.79 & 66 \\
\hline Fe & $5.4 \pm 0.1$ & 1.5 & 72 \\
\hline Mn & $0.30 \pm 0.05$ & 0 & 100 \\
\hline Ni & $2.25 \pm 0.05$ & 0.73 & 68 \\
\hline Zn & $4.3 \pm 0.1$ & 1.6 & 63 \\
\hline
\end{tabular}


NF also resulted in a significant change to the color of the permeate compared to the feed and retentate (Figure 4). The lighter color in the permeate also probably reflects the retention of transition metals such as Fe, which often form highly colored co-ordination complexes. No such color change was detected during the MF step.

This means that nanofiltration may play a role in concentrating these multivalent salts into a retentate stream for further treatment or disposal. Removal of elements such as $\mathrm{Fe}$ is important, as these are strongly associated with corrosion [26] and can catalyse oxidative amine degradation[27]. This would require the use of a larger pore size NF membrane, to provide greater flux values, but such membranes are readily available and should be the focus of further work. The NF permeate would then be a solution of MEA containing only monovalent salts, which might be more readily treated by electrodialysis as discussed below.

\subsection{Electrodialysis}

As expected, electrodialysis showed a significant ion transport from the feed (diluate) to the concentrate solution for both the MEA50+ and the MEA 1800+ (Figure 5). The conductivity of the electrode solution also reduced slightly over time, indicating the transport of some ions from the electrode solution to the concentrate. Transport of iron and/or organic matter was also indicated by a gradual change in the colour of the concentrate solution from clear to brown, similar to the colour of the feed solution.

The greater increase in the concentrate conductivity relative to the decrease in diluate conductivity is due to the significant organic content of the feed solutions. Since an organic solution has a lower conductance compared to a purely aqueous solution, the nominal value of the solution conductivity does not represent the amount of ions in the system. For the MEA50+ solution, the conductivity of the diluate was reduced from 12.8 to $1.1 \mathrm{mS} / \mathrm{cm}$ in 960 minutes of operation, representing 91\% removal of all charged species. Similarly, for the MEA1800+, the conductivity was reduced from 15.6 to $8.4 \mathrm{mS} / \mathrm{cm}$ in 790 minutes, a loss of $46 \%$. The use of a larger membrane area relative to the batch size would reduce these timeframes.

The $\mathrm{pH}$ of all the working solutions was also monitored (Figure 6). Even before the application of an electrical potential (-20 to 0 minutes), the $\mathrm{pH}$ of the concentrate and 
electrode solution increased. Within this initial period, the $\mathrm{pH}$ of both solutions had increased from $4-8$ initially to around 10 . This finding reflects the high mobility of $\mathrm{OH}^{-}$and $\mathrm{H}^{+}$ions which means that they permeate the membranes readily without the need for a driving electrical potential. Once the voltage was applied, the concentrate $\mathrm{pH}$ continued to drift up slowly, with the diluate solution drifting down, reflecting continuing transfer of $\mathrm{OH}^{-}$ions from the diluate to the concentrate. The drift in concentrate $\mathrm{pH}$ is greater in the first 600 minutes for the MEA50+ experiment, which may indicate that some water splitting is also occurring, given the relatively low diluate solution conductivity ( $<13 \mathrm{mS} / \mathrm{cm}$ throughout). Similarly, the upturn in concentrate $\mathrm{pH}$ with MEA1800+ after around 600 minutes may represent the onset of water splitting as the concentration of available ions in the diluate falls below $10 \mathrm{mS} / \mathrm{cm}$.

These conclusions are supported by the calculation of the overall current efficiency for the experiments, based on the total cations transferred to the concentrate. This current efficiency is $92 \%$ for the MEA1800+ experiment, indicating that such water splitting is not significant throughout most of the experiment.. Conversely, the overall current efficiency for the MEA50+ experiment is calculated as only $70 \%$, indicative of significant water splitting consuming the electrical charge due to the low diluate concentration.

These decreasing rates of transfer from the diluate to the concentrate as time progresses are evident from Figure 7 and Figure 8, which show the concentrations of various elements in the concentrate versus time. For sodium, nickel, iron, silicon and nitrate the concentrations plateaued after $\sim 500 \mathrm{~h}$ for MEA 50+. However the concentration of sulfate transferred from both MEA50+, and MEA1800+ had not plateaued even after 1000 minutes. The total transfer of multivalent metal ions (such as $\mathrm{Ca}, \mathrm{Fe}, \mathrm{Mn}, \mathrm{Zn}$ ) to the concentrate is low (Table 4), relative to their feed concentrations (Figure 2). In particular, the total transfer of iron cations is only $46 \%$ for the MEA50+ experiment and 19\% for the MEA1800+ experiment. This indicates that these larger [28] multivalent ions are transferred less readily than the dominant monovalent sodium and potassium cations.

The concentrations of sodium and potassium in the final concentrate (Table 4) are significantly higher than those of the other cations, reflecting their initially high concentrations within the neutralised feed (after $\mathrm{NaOH}$ addition equivalent to 20 and $27 \mathrm{~g} / \mathrm{L}$ $\mathrm{Na}$ for MEA50+ and MEA1800+ respectively), concentrate (5 g/L KCl) and electrode (50 $\mathrm{g} / \mathrm{L} \mathrm{K}_{2} \mathrm{SO}_{4}$ ) solutions. As expected from Figure 1, there is transfer of potassium from the 
electrode solution to the concentrate and a similar transfer of sodium from the diluate to the electrode solution. While these flows are substantial in the two cell system used here, they would be much less significant within a larger system.

The sulphate and nitrate anion concentrations are also significant, indicating that they existed within the feed at high concentrations. Indeed, independent measurements from similar MEA solutions from the same pilot plant gave 1500-2400 ppm sulfate and 600-1500 ppm nitrate [29]. This is reasonably consistent with the data presented here and equates to a slip of $\mathrm{SO}_{2}$ and NOx (other than NO) of less than $1 \mathrm{ppm}$ each from the flue gas pretreatment process into the $\mathrm{CO}_{2}$ absorber unit. The sulphate content measured by ion chromatography and reported in Table 4 (510 and 1970 ppm) is reasonably consistent with that calculated from sulfur analysis using ICP (610 and 1500 ppm) indicating that the main sulfur compound is indeed sulfate $\left(\mathrm{SO}_{4}{ }^{2-}\right)$ and not sulfite $\left(\mathrm{SO}_{3}{ }^{-}\right)$. It is noteworthy that while the nitrate transfer in both experiments tends to plateau at longer time frames, the sulphate concentration continues to increase (Figure 8). This suggests that the nitrate ion is more readily transferred and so reaches equilibrium earlier than the sulphate ion. This is consistent with the discussion of cation transfer - the smaller, monovalent nitrate ion (0.335 nm hydrated radius [28]) moves faster than the larger multivalent sulphate ion (0.379 $\mathrm{nm}$ hydrated radius [28]).

Table 4 - Final Concentrate Composition following Electrodialysis (mg/L) and the percentage transferred (where data is available).

\begin{tabular}{|c|c|c|c|c|c|c|}
\hline & & & \multicolumn{2}{|c|}{ MEA50+ Experiment } & \multicolumn{2}{|c|}{ MEA1800+ Experiment } \\
\hline & & & $\begin{array}{c}\text { Concentrate } \\
(\mathrm{g} / \mathrm{L})\end{array}$ & $\begin{array}{c}\% \\
\text { Transferred }\end{array}$ & $\begin{array}{c}\text { Concentrate } \\
(\mathrm{g} / \mathrm{L})\end{array}$ & $\begin{array}{c}\% \\
\text { Transferred }\end{array}$ \\
\hline \multirow[t]{13}{*}{ Cations } & $\mathbf{K}$ & & 18,200 & & 10,500 & \\
\hline & $\mathbf{N a}$ & & 4,140 & & 9,900 & \\
\hline & Ca & & 2.7 & $100 \%$ & 2.5 & 34 \\
\hline & Cd & & 0 & & 0 & \\
\hline & $\mathrm{Cr}$ & & 0.06 & & 0.0 & \\
\hline & $\mathbf{C u}$ & & 0 & & 0.1 & \\
\hline & Fe & & 0.6 & 46 & 8.1 & 19 \\
\hline & Mg & & 0.02 & & 0.09 & \\
\hline & Mn & & 0.05 & 55 & 0.06 & 10 \\
\hline & Mo & & 0.19 & & 0.21 & \\
\hline & $\mathbf{N i}$ & & 0.45 & & 0.06 & \\
\hline & $\mathbf{V}$ & & 0.006 & & 0.10 & \\
\hline & Zn & & 0.97 & 87 & 0.29 & 7 \\
\hline \multirow[t]{3}{*}{ Anions } & Sulfate & $\mathrm{SO}_{4}$ & 510 & & 1,970 & \\
\hline & Nitrate & $\mathrm{NO}_{3}$ & 62 & & 1,890 & \\
\hline & Silicon & $\mathrm{Si}$ & 15 & & 2.0 & \\
\hline
\end{tabular}


Additionally, MEA permeation across the ion-exchange membranes was confirmed by titration. As shown in Figure 9, permeation is evident from both the fall in the diluate concentration and the increase in the concentrate. The permeation rate estimated from the concentrate data is $0.16 \mathrm{~g} / \mathrm{m}^{2} . \mathrm{s}$ for the MEA50+ and $0.14 \mathrm{~g} / \mathrm{m}^{2} . \mathrm{s}$ for the MEA1800+; consistent with the estimate of $0.17 \mathrm{~g} / \mathrm{m}^{2} . \mathrm{s}$ estimated in our earlier laboratory work [15]. Most of this transfer is free amine, but there is also some carbamate or carbonate anion transfer, consistent with the non-zero $\mathrm{CO}_{2}$ loading of the solution and the significantly lower rates of amine transfer into the electrode tank (data not shown).

A charge balance over the concentrate solution, taking into account the carbamate/carbonate anion transfer described above as well as hydroxide anion transfer, suggests that the concentration of organic anions (formate, acetate, oxalate) are relatively low in the MEA50+, but significant within the MEA1800+ feed solution.

In industrial practice, the ED process would probably not be operated as a batch process, as used in these laboratory experiments, but rather run as a continuous process, on a slip stream of lean solvent. In this case, it will be important to optimise the steady state concentration of heat stable salts that should be utilised. If this is too low, then the neutralised solution conductivity will also be low, as in the case of the present MEA50+ solution, leading to low current efficiencies and thus higher energy demand. Conversely, if the heat stable salt concentrations are too high, corrosion and foaming issues may occur within the main solvent absorption process. It will also be necessary to carefully manage the sodium ion concentration that is added during neutralisation, as this is a major contributor to the solution conductivity and thus to the energy requirements for electrodialysis.

\subsection{Membrane stability}

The NF and ED membranes were soaked in the aged MEA solvents for a period of 4.5 months. ATR-FTIR analysis indicated that the MPF-34 and Neosepta CEM membranes are stable over this period (data not shown). However, an unexplained change in the membrane composition of the Neosepta AEM is observed within the wavenumber range of 1800 to 1270 $\mathrm{cm}^{-1}$ (Figure 10). This change was not observed when the same membrane was soaked for a similar period in a laboratory prepared $30 \mathrm{wt} \%$ MEA solution[15]. The membrane is understood to be manufactured with quaternary amine functionality [30] and it is possible that the membrane is forming a salt with carbonate ions present in the solution. A typical 
peak for carbonates occurs at $1388 \mathrm{~cm}^{-1}$ while that for bicarbonates is at 1298 and $1360 \mathrm{~cm}^{-1}$ [31]. The occurrence of the peaks in the range of 1079 to $869 \mathrm{~cm}^{-1}$ and the shoulder at 1645 to $1600 \mathrm{~cm}^{-1}$ are probably related to residual MEA solution within the membrane and on the membrane surface[31, 32]. The broadening of the peak in the range $3000-3500 \mathrm{~cm}^{-1}$ is indicative of water sorption.

\section{Conclusions and Recommendations}

This work has clearly shown the potential of electrodialysis as a mechanism to purify MEA solvents during carbon capture applications. Between 46 and 91\% of the ionic content was removed from an industrial aged MEA solvent after neutralisation, using this approach. However, the electrodialysis process as used here was more effective in removing the small monovalent ions such as sodium, potassium and nitrate. It was less efficient at removing larger multivalent ions such as iron and sulphate. Future work could focus on testing membranes that are more effective at removing these larger ions. There was also some evidence that the anion exchange membrane used was affected by exposure to the contaminated amine and other membranes should be evaluated for greater resilience.

The work presented here was conducted in a 'batch mode' leading to low current efficiencies when the diluate conductivity fell below $10 \mathrm{mS} / \mathrm{cm}$. In a full scale capture operation, it is likely to be more practical and economically effective to run a continuous operation on a slipstream of cool, lean solvent. This would avoid the loss in current efficiency observed here when the batch process was continued to very low diluate concentrations.

Nanofiltration was also investigated but membrane permeation rates were very low, reflecting the high salt concentrations and non-zero $\mathrm{CO}_{2}$ loadings. Further work might focus on the use of MEA solutions with lower $\mathrm{CO}_{2}$ loadings and a membrane of larger pore size to facilitate greater flux. However, this approach had the advantage of concentrating larger multivalent ions such as iron into the retentate. It thus may play a role in concentrating such impurities for removal in some circumstances. The permeate, free of multivalent ions, could then be more effectively processed through an electrodialysis operation. 


\section{Acknowledgements}

The authors acknowledge the financial support provided by the Australian Government through its Cooperative Research Centre program and that provided directly through Australian National Low Emissions Coal Research Development (ANLEC R\&D). ANLEC R\&D is supported by Australian Coal Association Low Emission Technology Limited and the Australian Government through the Clean Energy Initiative. The authors also wish to acknowledge financial assistance provided through BCIA. BCIA is a private member-based company with funding contracts through ANLEC R\&D and the Victorian State Government Department of Sustainable Development and Business Innovation. Alicia Reynolds acknowledges the provision of a Brown Coal Innovation Australia (BCIA) research scholarship, an Australian Postgraduate Award scholarship and support from AGL Loy Yang for her Ph.D. research on post-combustion capture of $\mathrm{CO}_{2}$.

The authors gratefully acknowledge AGL Loy Yang power plant for hosting CSIRO's PCC pilot plant on their site and James Jansen, Sascha Voigt and Neil Slater for operating the plant throughout the campaign.

\section{References}

[1] M.E. Boot-Handford, J.C. Abanades, E.J. Anthony, M.J. Blunt, S. Brandani, N. Mac Dowell, J.R. Fernandez, M.-C. Ferrari, R. Gross, J.P. Hallett, R.S. Haszeldine, P. Heptonstall, A. Lyngfelt, Z. Makuch, E. Mangano, R.T.J. Porter, M. Pourkashanian, G.T. Rochelle, N. Shah, J.G. Yao, P.S. Fennell, Carbon capture and storage update, Energy \& Environmental Science, 7 (2014) 130-189.

[2] L. Dumée, C. Scholes, G. Stevens, S. Kentish, Purification of aqueous amine solvents used in post combustion CO 2 capture: A review, International Journal of Greenhouse Gas Control, 10 (2012) 443-455.

[3] A. Reynolds, V. Verheyen, S. Adeloju, E. Meuleman, P. Feron, Towards commercial scale post-combustion capture of $\mathrm{CO} 2$ with monoethanolamine solvent: key considerations for solvent management and environmental impacts, Environmental Science \& Technology, 46 (2012) 3643-3654.

[4] G.S. Goff, G.T. Rochelle, Monoethanolamine Degradation: $\mathrm{O}_{2}$ Mass Transfer Effects under $\mathrm{CO}_{2}$ Capture Conditions, Industrial \& Engineering Chemistry Research, 43 (2004) 6400-6408.

[5] T. Supap, R. Idem, P. Tontiwachwuthikul, C. Saiwan, Kinetics of sulfur dioxide- and oxygen-induced degradation of aqueous monoethanolamine solution during $\mathrm{CO}_{2}$ absorption from power plant flue gas streams, International Journal of Greenhouse Gas Control, 3 (2009) 133-142. 
[6] B.R. Strazisar, R.R. Anderson, C.M. White, Degradation Pathways for Monoethanolamine in a CO2 Capture Facility, Energy and Fuels, 17 (2003) 1034-1039.

[7] S. Chi, G.T. Rochelle, Oxidative Degradation of Monoethanolamine, Industrial \& Engineering Chemistry Research, 41 (2002) 4178-4186.

[8] W. Conway, X. Wang, D. Fernandes, R. Burns, G. Lawrance, G. Puxty, M. Maeder, Comprehensive Kinetic and Thermodynamic Study of the Reactions of $\mathrm{CO}_{2}(\mathrm{aq})$ and $\mathrm{HCO}_{3}{ }^{-}$ with Monoethanolamine (MEA) in Aqueous Solution, The Journal of Physical Chemistry A, 115 (2011) 14340-14349.

[9] H.J. Liu , J.W. Dean, S. F. Bosen, Neutralization Technology to Reduce Corrosion from Heat Stable Amine Salts, in: NACE International Corrosion Conference \& Expo, Orlando, Florida, 1995.

[10] A. Aboudheir, W. ElMoudir, J. Fairchild, HTC's Delta Reclaimer for Purifying Contaminated Solvents, Carbon Capture Journal Jan/Feb (2015) 21-24.

[11] H. Strathman, Ion-exchange membrane separation processes, in: S. Heiner (Ed.) Membrane science and technology series, Elsevier, 2004.

[12] S.E. Kentish, E. Kloester, G.W. Stevens, C.A. Scholes, L. Dumée, Electrodialysis in aqueous-organic mixtures, Separation and Purification Reviews, 44 (2015) 269-282.

[13] A. Sexton, K. Dombrowski, P. Nielsen, G. Rochelle, K. Fisher, J. Youngerman, E. Chen, P. Singh, J. Davison, Evaluation of Reclaimer Sludge Disposal from Post-combustion $\mathrm{CO}_{2}$ Capture, Energy Procedia, 63 (2014) 926-939.

[14] A. Volkov, V. Vasilevsky, S. Bazhenov, V. Volkov, A. Rieder, S. Unterberger, B. Schallert, Reclaiming of Monoethanolamine (MEA) Used in Post-Combustion $\mathrm{CO}_{2}$-capture with Electrodialysis, Energy Procedia, 51 (2014) 148-153.

[15] J. Lim, A. Aguiar, C.A. Scholes, L.F. Dumée, G.W. Stevens, S.E. Kentish, Monoethanolamine Reclamation Using Electrodialysis, Industrial \& Engineering Chemistry Research, 53 (2014) 19313-19321.

[16] J. Lim, C.A. Scholes, L.F. Dumée, S.E. Kentish, Nanofiltration for the concentration of heat stable salts prior to MEA reclamation, International Journal of Greenhouse Gas Control, 30 (2014) 34-41.

[17] F. Vitse, B. Baburao, R. Dugas, L. Czarnecki, C. Schubert, Technology and pilot plant results of the advanced amine process, Energy Procedia, 4 (2011) 5527-5533.

[18] S. Bazhenov, V. Vasilevsky, A. Rieder, S. Unterberger, E. Grushevenko, V. Volkov, B. Schallert, A. Volkov, Heat Stable Salts (HSS) Removal by Electrodialysis: Reclaiming of MEA Used in Post-combustion CO2-Capture, Energy Procedia, 63 (2014) 6349-6356.

[19] M. Azzi, A. Tibbett, B. Halliburton, A.Element, Y.Artanto, E. Meuleman, P. Feron, Assessing Atmospheric Emissions from Amine-based $\mathrm{CO}_{2}$ Post-combustion Capture Processes and their Impacts on the Environment - A Case Study. Global CCS Institute, Commonwealth Scientific and Industrial Research Organisation (CSIRO) (2014).

[20] A.J. Cottrell, J.M. McGregor, J. Jansen, Y. Artanto, N. Dave, S. Morgan, P. Pearson, M.I. Attalla, L. Wardhaugh, H. Yu, A. Allport, P.H.M. Feron, Post-combustion capture R\&D and pilot plant operation in Australia, Energy Procedia, 1 (2009) 1003-1010.

[21] Y. Artanto, J. Jansen, P. Pearson, T. Do, A. Cottrell, E. Meuleman, P. Feron, Performance of MEA and amine-blends in the CSIRO PCC pilot plant at Loy Yang Power in Australia, Fuel, 101 (2012) 264-275. 
[22] G. Astarita, G. Marrucci, F. Gioia, The influence of carbonation ratio and total amine concentration on carbon dioxide absorption in aqueous monoethanolamine solutions, Chemical Engineering Science, 19 (1964) 95-103.

[23] A.L. Cummings, F.C. Veatch, A.E. Keller, S.M. Mecum, R.M. Kammiller, An analytical method for determining bound and free alkanolamines in heat stable salt contaminated solutions, in: AIChE 1990 Summer National Meeting Symposium on Gas Processing, Ponca City, OK, 1990.

[24] S. Williams, Official methods of analysis of the Association of Official Analytical Chemists, 1984.

[25] R.H. Weiland, J.C. Wingman, D.B. Cronin, G.J. Browning, Density and Viscosity of Some Partially Carbonated Aqueous Alkanolamine Solutions and Their Blends, Journal of Chemical \& Engineering Data, 43 (1998) 378-382.

[26] G.S. Goff, G.T. Rochelle, Oxidation inhibitors for copper and iron catalyzed degradation of monoethanolamine in $\mathrm{CO} 2$ capture processes, Industrial and Engineering Chemistry Research, 45 (2006) 2513-2521.

[27] S. Chi, G.T. Rochelle, Oxidative degradation of monoethanolamine, Industrial \& Engineering Chemistry Research, 4 (2002) 4178-4186.

[28] E.R. Nightingale, Phenomenological Theory of Ion Solvation. Effective Radii of Hydrated Ions, The Journal of Physical Chemistry, 63 (1959) 1381-1387.

[29] A.J. Reynolds, T.V. Verheyen, S.B. Adeloju, A. Chaffee, E. Meuleman, Primary sources and accumulation rates of inorganic anions and dissolved metals in a MEA absorbent during PCC at a brown coal-fired power station, International Journal of Greenhouse Gas Control, Accepted for International Journal of Greenhouse Gas Control, 2015 (http://dx.doi.org/10.1016/i.ijggc.2015.07.004)

[30] F. Durmaz, H. Kara, Y. Cengeloglu, M. Ersoz, Fluoride removal by donnan dialysis with anion exchange membranes, Desalination, 177 (2005) 51-57.

[31] G. Richner, G. Puxty, Assessing the Chemical Speciation during CO2 Absorption by Aqueous Amines Using in Situ FTIR, Industrial \& Engineering Chemistry Research, 51 (2012) 14317-14324.

[32] Monoethanolamine, in: National Institute of Standards and Technology Chemistry Webbook, 2011. 


\section{Figure Captions}

Figure 1 - A schematic diagram of the ED rig. Diluate = the feed MEA solution that is gradually depleted of ionic impurities. Concentrate $=$ the aqueous solution that is gradually gaining the ionic impurities. $\mathrm{CEM}=$ cation exchange membrane, $\mathrm{AEM}=$ anion exchange membrane.

Figure 2 - The concentration of specific metal cations in the two aged solvents as received.

Figure 3 - The permeate flux for 30 wt\% MEA (laboratory prepared), MEA50+ (after thermal boiling and neutralisation) and MEA1800+ (after neutralisation) at different pressures using an MPF-34 nanofiltration membrane. Experiments were conducted both before and after microfiltration (MF) but with little change in results.

Figure 4 - Visual appearance of the MEA samples before and after nanofiltration at 3000 $\mathrm{kPa}$. The top set of images are MEA50+, while the lower are MEA1800+ (a) feed (b) retentate and (c) permeate.

Figure 5 - The change in the diluate, concentrate and electrode solution conductivity over time (a) MEA50+ (b) MEA 1800+. ( $\boldsymbol{\Delta}$ ) Electrode $(\diamond)$ Concentrate ( $\boldsymbol{( \boldsymbol { c } )}$ ) Diluate

Figure 6 - The change in the diluate, concentrate and electrode solution $\mathrm{pH}$ over time (a) MEA50+ (b) MEA 1800+. ( $\mathbf{\Delta})$ Electrode $(\diamond)$ Concentrate ( $\boldsymbol{\square})$ Diluate. The solutions were circulated through the membrane cells for 20 minutes prior to the initial application of an electrical potential, which is defined here as time $=0$.

Figure 7 - Elemental analysis ( $\mathrm{Na}, \mathrm{Fe}, \mathrm{Ni}$ and $\mathrm{Si}$ ) of the concentrate during electrodialysis of the (a) MEA50+ and (b) MEA 1800+ solutions.

Figure 8 - Sulfate and nitrate concentration in the concentrate solution during electrodialysis of (a) MEA50+ (b) MEA1800+

Figure 9 - MEA concentration in the diluate and concentrate solution (a) MEA50+ (b) MEA 1800+. (•) Total Amine ( $($ ) Free Amine.

Figure 10 - The ATR-FTIR spectra for Neosepta anion exchange membranes soaked in aged industrial solvents. The solvents were as received, without neutralization or boiling. 


\section{Unit cell}

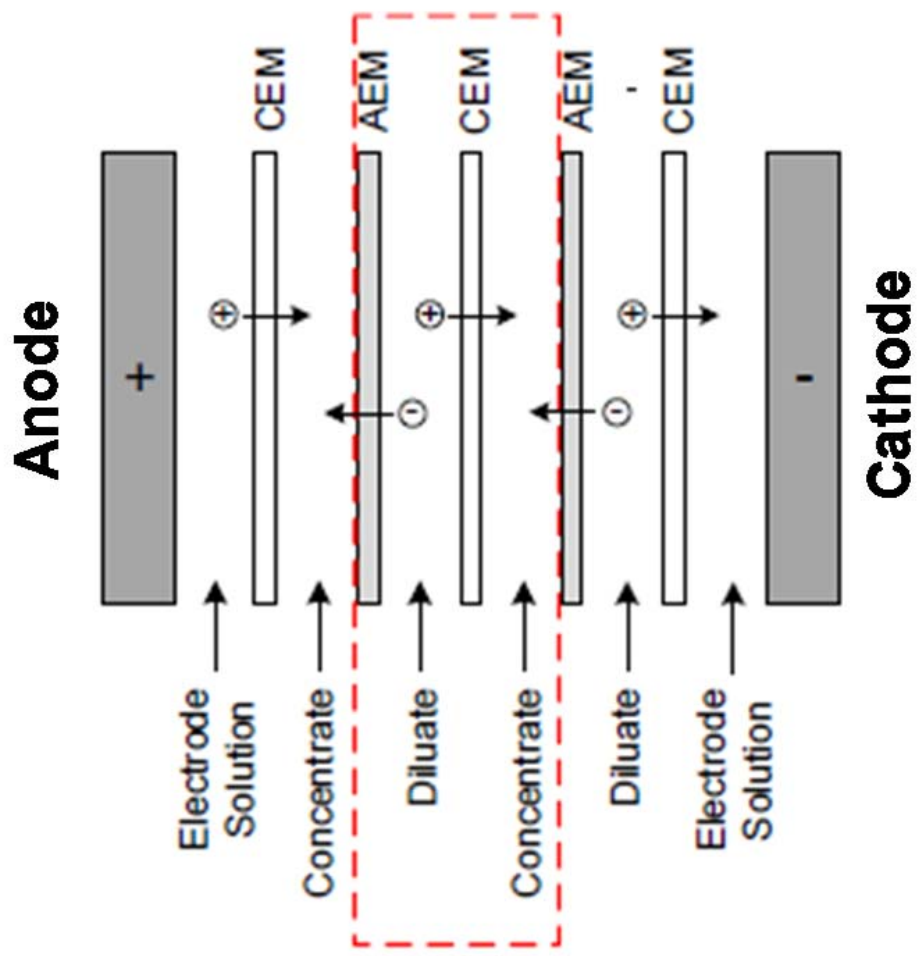




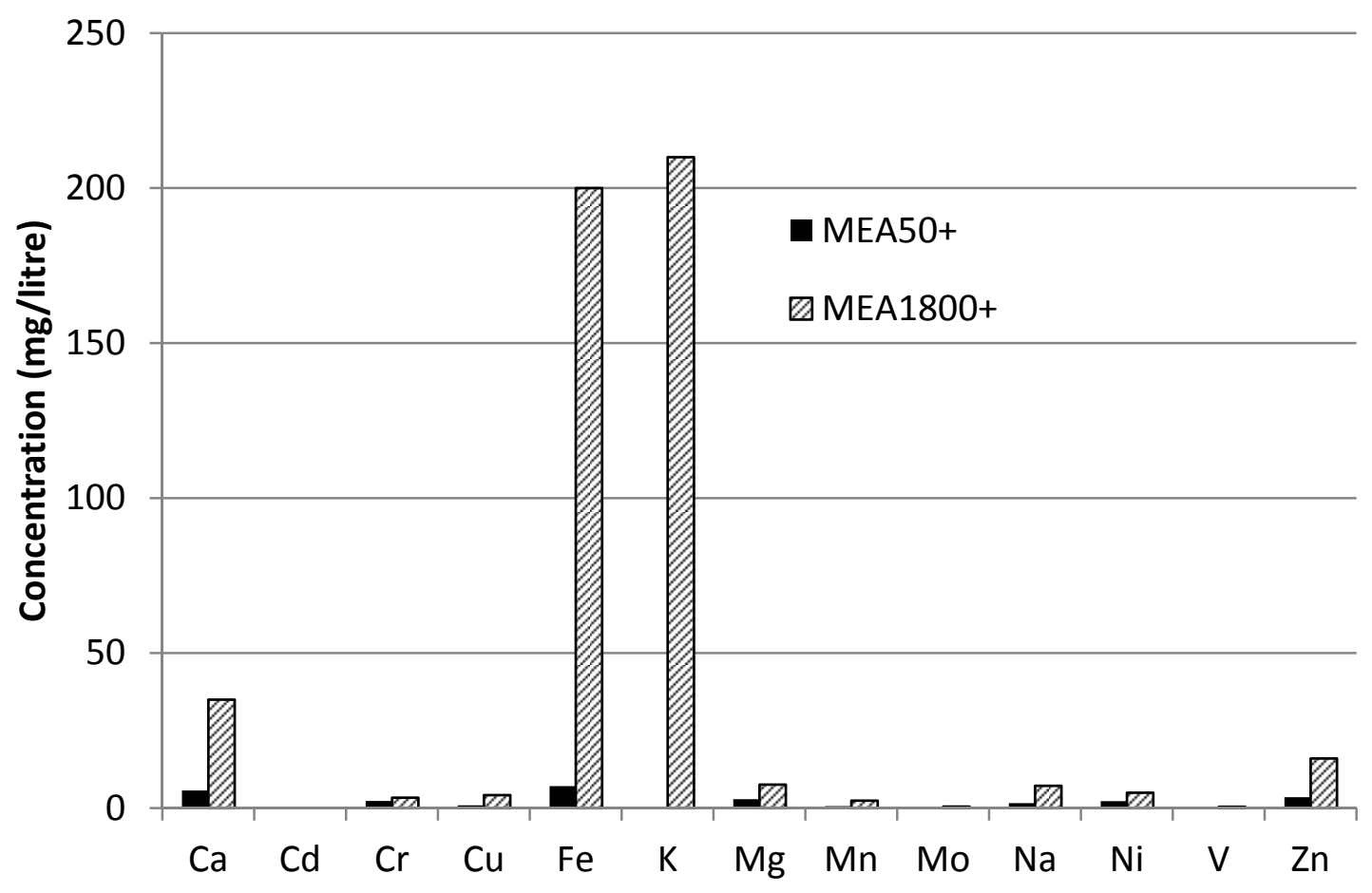




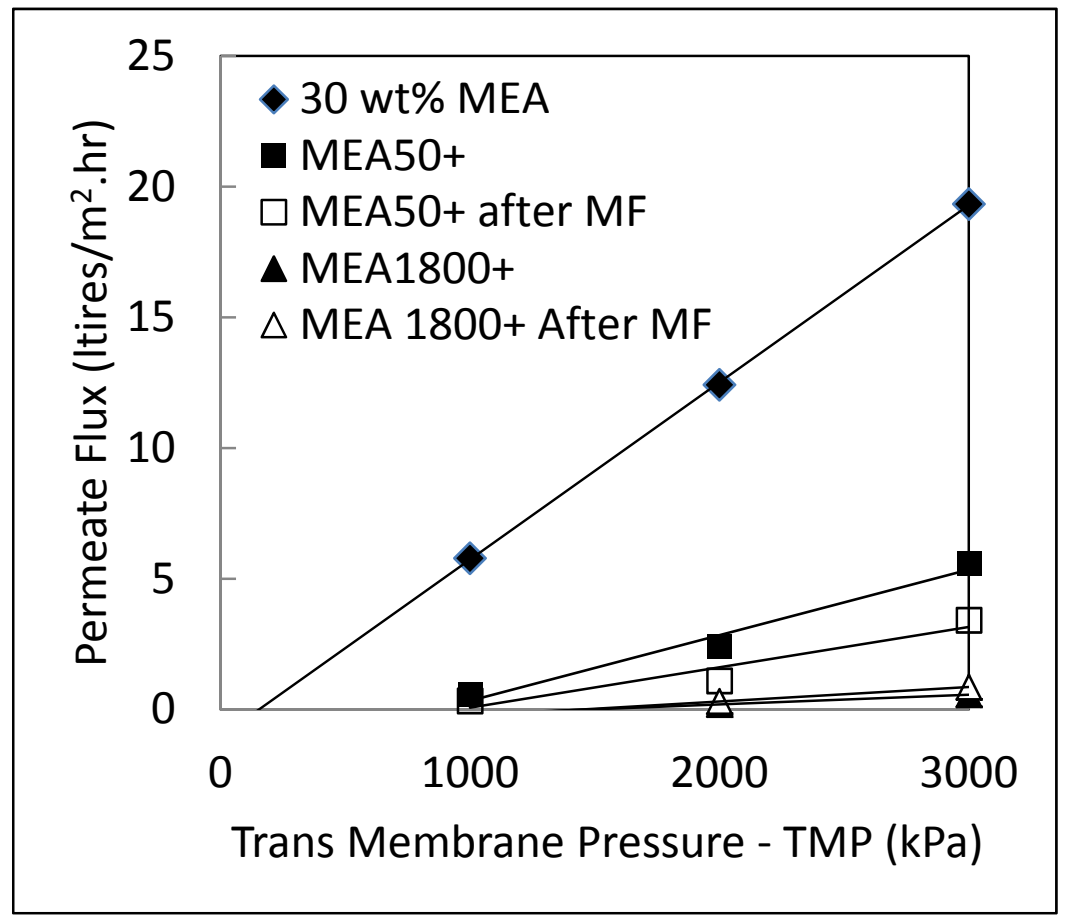



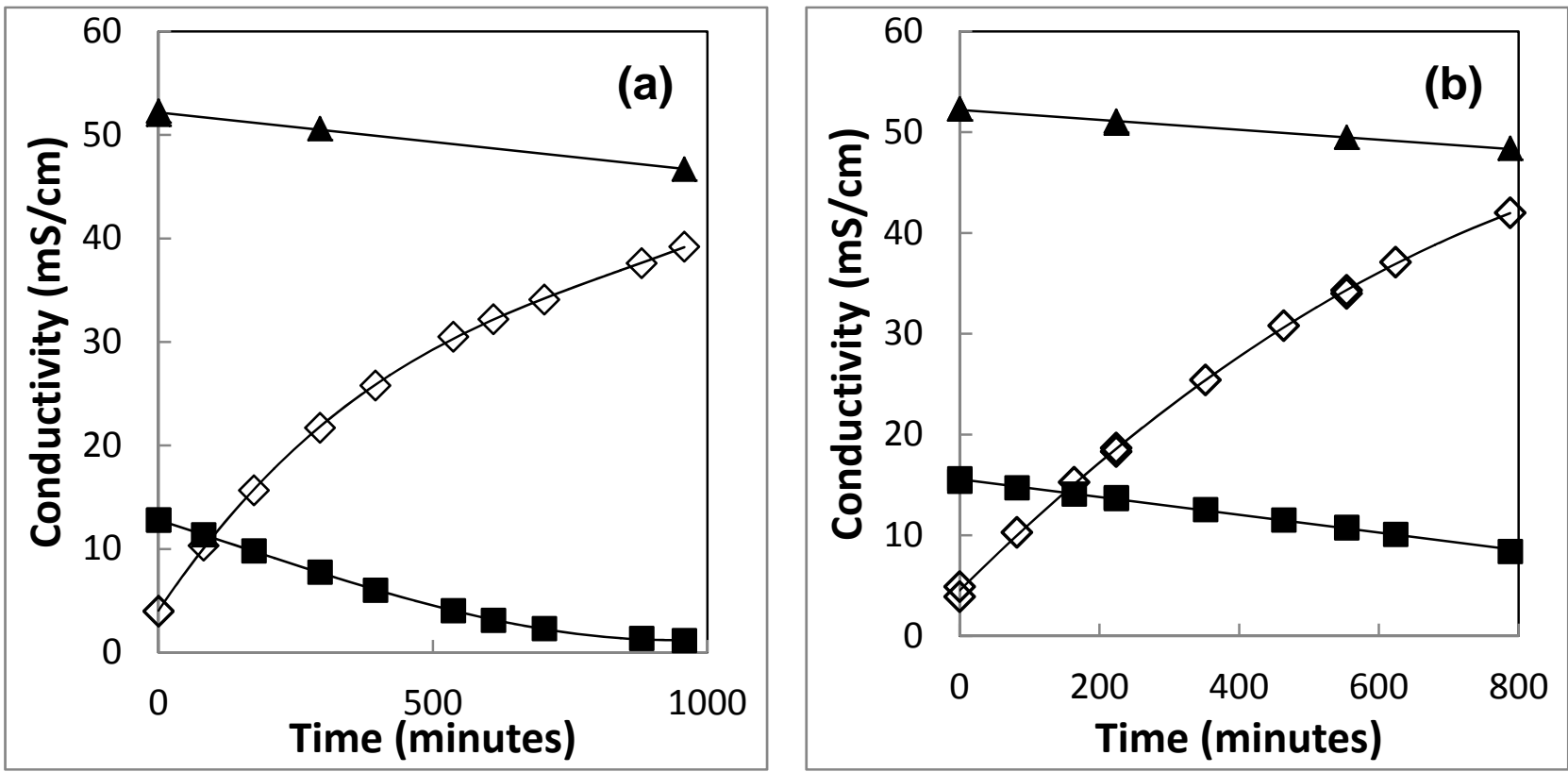

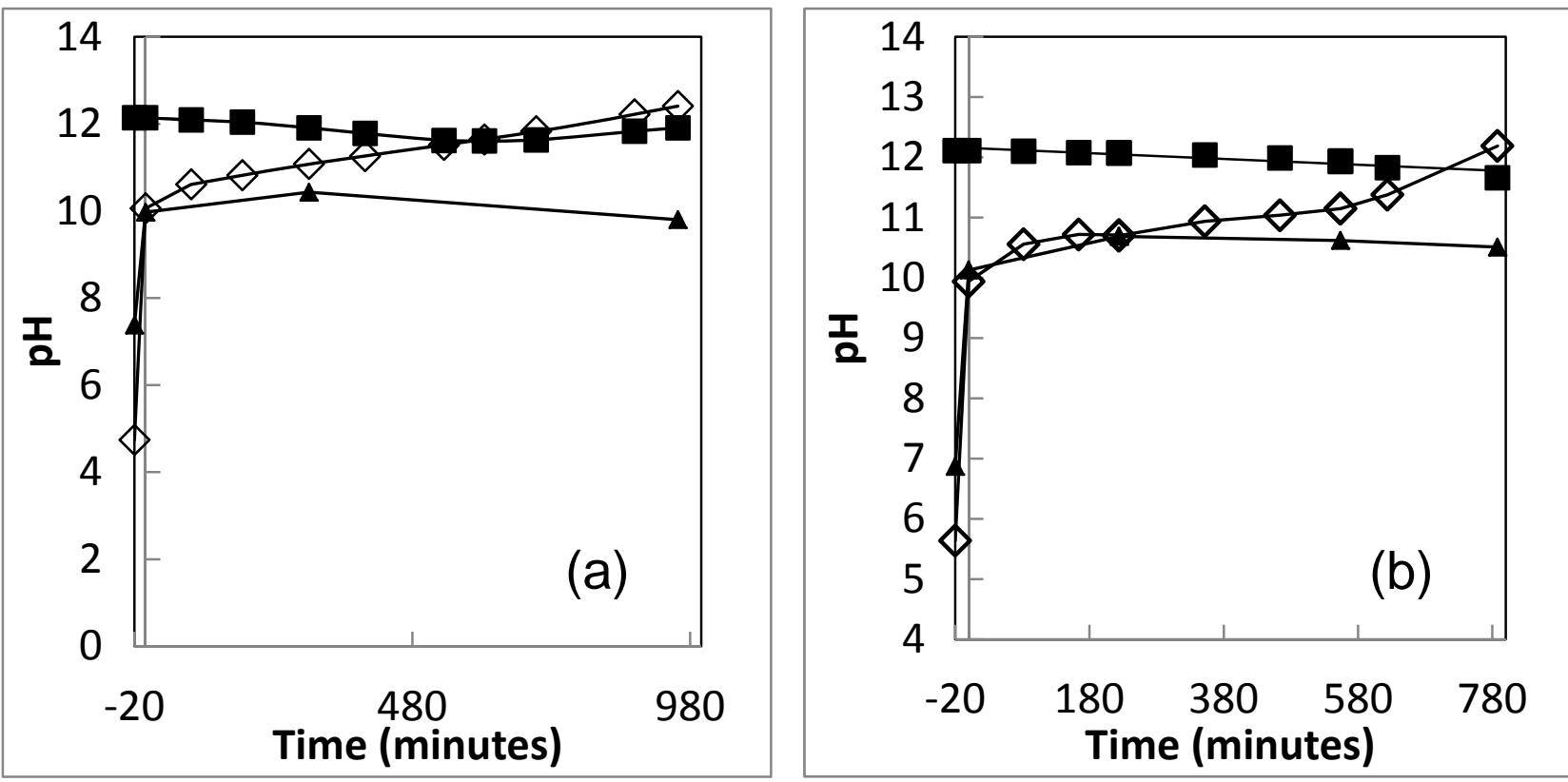

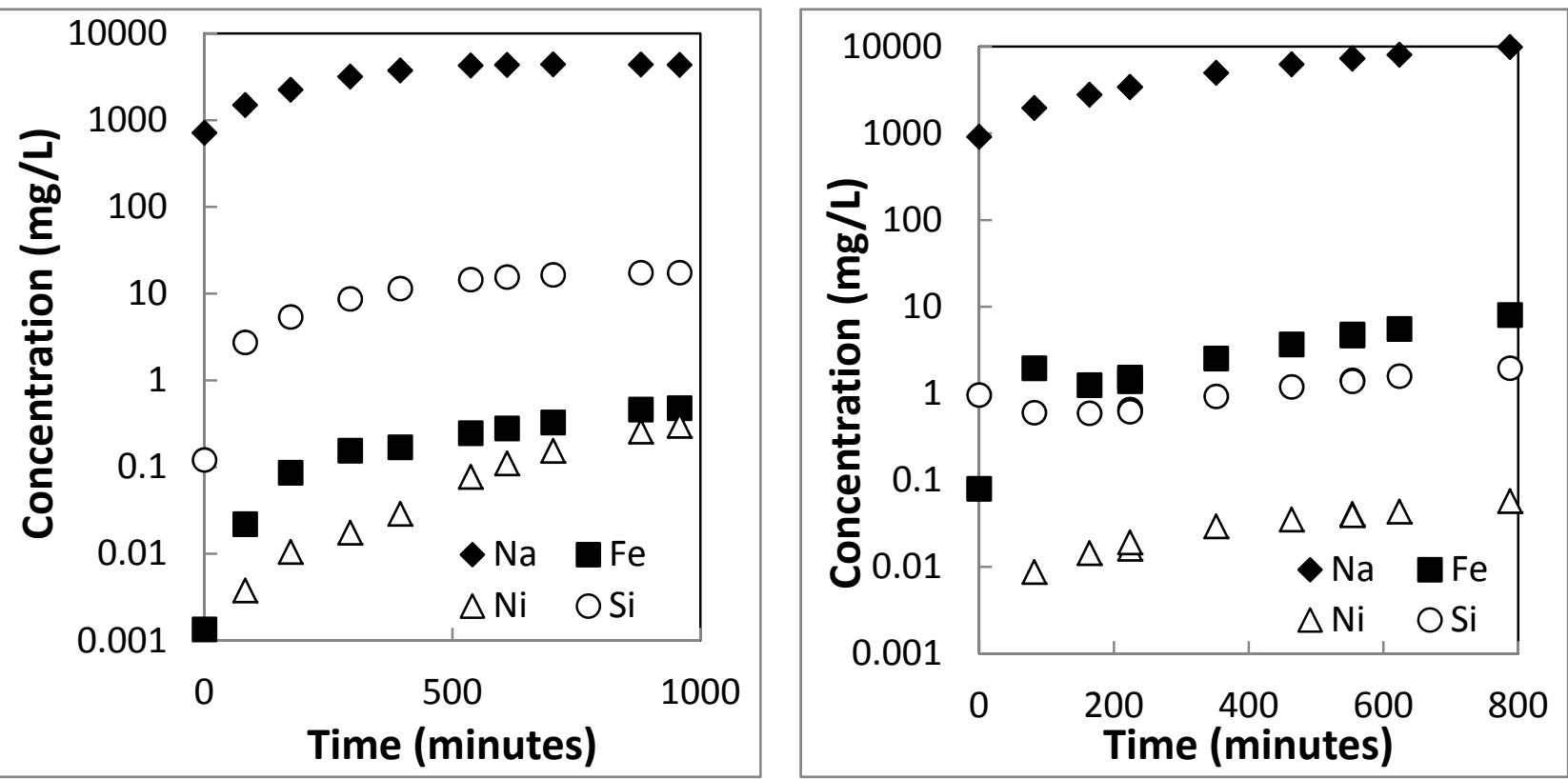

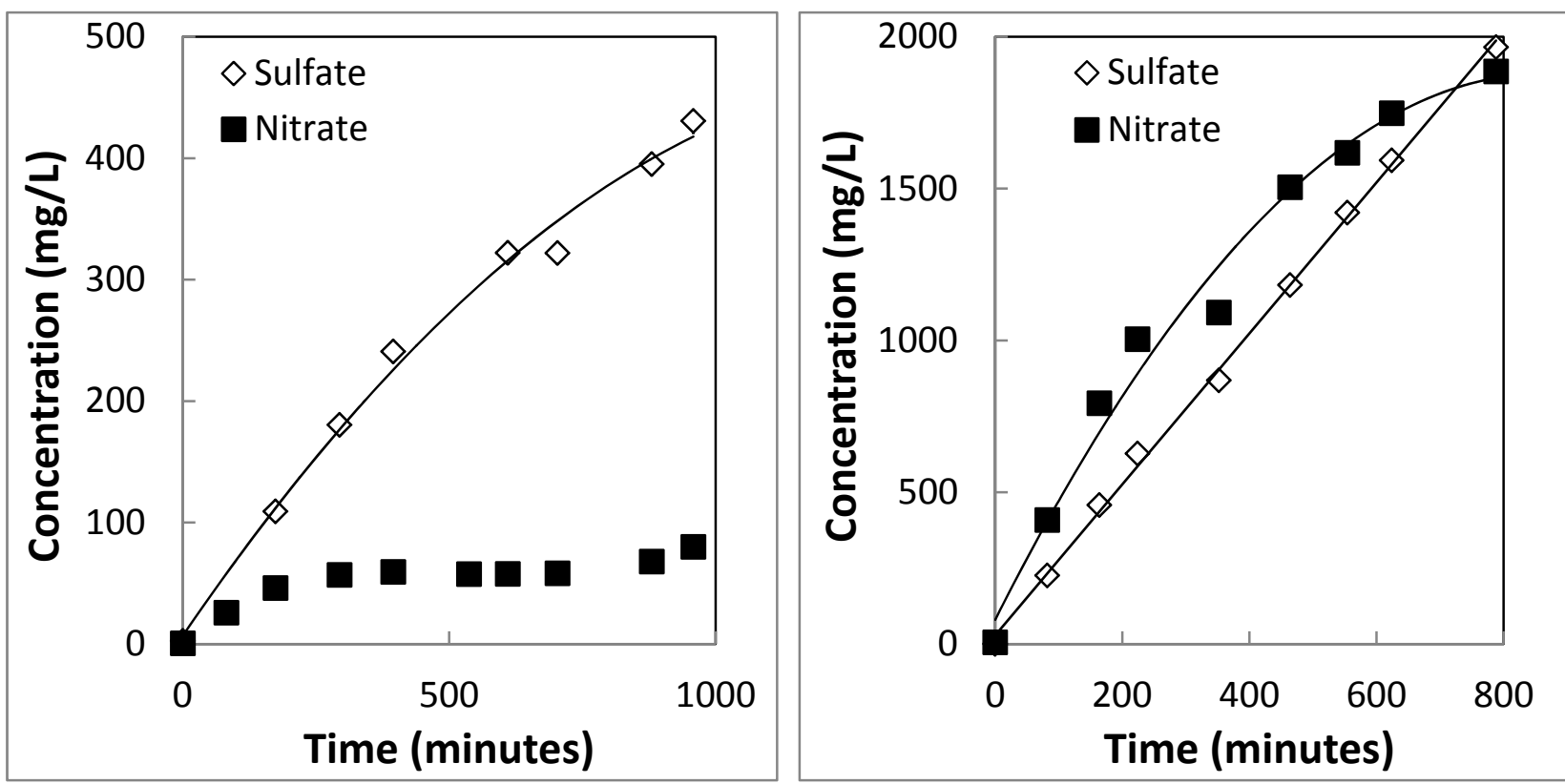


\section{University Library}

\section{- M M N E R VA A gateway to Melbourne's research publications}

Minerva Access is the Institutional Repository of The University of Melbourne

Author/s:

Lim, J;Aguiar, A;Reynolds, A;Pearson, P;Kentish, SE;Meuleman, E

Title:

Remediation of monoethanolamine after exposure to brown coal flue gases

Date:

2015-11-01

Citation:

Lim, J., Aguiar, A., Reynolds, A., Pearson, P., Kentish, S. E. \& Meuleman, E. (2015).

Remediation of monoethanolamine after exposure to brown coal flue gases.

INTERNATIONAL JOURNAL OF GREENHOUSE GAS CONTROL, 42, pp.545-553. https:// doi.org/10.1016/j.ijggc.2015.09.004.

Persistent Link:

http://hdl.handle.net/11343/56944 